\title{
Disciplining thought: between ideology and anything goes
}

\author{
Paul Standish (UCL Institute of Education)
}

\begin{abstract}
Educational research is subject to orthodoxies of old and novel kinds. The 'foundations' approach risks becoming stuck in footnotes to received ideas, while new-fangled disciplines seek to legitimate themselves in jargon and deference to new 'authorities'. The critical deficit in both tendencies stands obstructs responsible enquiry. I begin by sketching the weaknesses and the potential of the foundations approach and go on to identify a range of threats to this potential. The first and major concern is the rise of empiricism, understood as the view that it is only through empirical enquiry that research into education can take place. A second concern is the dominance of English in educational research, in relation not only to the inevitable unfairness this brings in opportunities for publication but also to the substance of thought and enquiry. Exploration of the key terms in David Bridges's "Rigour", "discipline" and the "systematic" in educational research' - and why they matter' (this issue) frames the discussion, raising questions of inter- and multidisciplinarity. There is an internal relation between discipline, rigour, and coherence, and these, though not systematicity, are requirements of argument. The notion of disciplined thought is prised apart from distorted conceptions of rigour and over-reliance on procedure.
\end{abstract}

We live in precarious times, in which the status and meaning of truth are being challenged in new ways. There are different truths, my facts are different from your facts, and Donald Trump is President of the United States of America. While there has been a relatively recent exacerbation of this trend in politics, it has been underway for some time in educational research. The source of this is said to be postmodernism, but this is an equivocal term at best. Sometimes it refers to a particular age (perhaps better described as 'postmodernity'), and sometimes it is connected, however questionably, to strands in poststructuralist thought. God is dead, and truth, Nietzsche said, is a woman, ${ }^{i}$ inaugurating a turn in thought that has sometimes been seen as the dislodging of the stone that led to the avalanche of postmodern undermining of truth, and so to relativism in multiple forms.

In his introduction to an extended symposium held at the European Conference in Educational Research in Copenhagen, 2017, with the title "Rigour", "discipline" and the "systematic" in the European educational research community? Fetish or fundamental?' (the products of which are collected in the present special issue), David Bridges draws attention to the 'post truth' politics that surrounds us now and provides a spirited and welcome defence against its influence in educational research (Bridges 2017). He quotes approvingly Kai Horstemke's remark that 'the current climate' is one 'in which truth, facts and rationality are treated with disdain' 
(Horstemke 2017: 274), and he offers an account of the disciplines in which rigour is seen as a cardinal virtue in the upholding of commitment to truth.

Bridges' defence of disciplinary foundations makes some important points. Disciplines in educational research are to be understood, he argues, as ways in which such qualities as rigour and scholarship have been and are organised and structured in that community: for different questions about education (or anything else) require different kinds of response, different forms of inquiry, different kinds of evidence, reasoning or argument. Things are far from straightforward here, however, as the development of the European Educational Research Association - including, in particular, its Philosophy of Education Network (Network 13) - has shown. It should certainly be recognised, he rightly asserts, that the forms that these 'disciplines' take have also evolved historically, in different ways in different places: Network 13 was not long established before it became clear that its participants were frequently talking past one another. This was a matter not just of being confronted by different languages but of facing up to the non-translatability of some of the language that was embedded in different national cultures. These are important points, about ways of thinking and about the significance of different languages, and I shall return to them below. But Bridges' conclusion embraces three broad statements, and it is to these that I would like first to turn. He claims:

[that] all research is logically associated with a requirement to seek to satisfy some kind of criterion of truthfulness; that this requires according to the nature of the inquiry the more or less rigorous application of certain procedural rules which help us to see what beliefs are most deserving of confidence and which, as Hunt has put it, 'make a community of arguers possible' (Hunt 1991:104); and that these procedural rules along with the body of work that has issued from [them] . . . constitute . . the 'disciplines' of knowledge. . . (Bridges 2017).

The logical progression between these points helps to show the need for some kind of community - or, at least, continuity - of enquiry between people, and the emphasis on procedural rules goes some way towards showing how the 'body of work' that characterises a discipline is constituted. That this is a community of 'arguers', and not, say, just adherents to a common cause, is one of the ways that this consolidation of practice becomes a discipline and avoids sliding into ideology.

Yet the very meaning of 'disciplines' in educational research is questioned, and the need for foundation subjects is surely contested. While some see education (understood, that is, as educational research) as a field dependent upon its constitutive disciplines (classically, history, psychology, philosophy, and sociology), others hold out for the idea that education is itself the discipline. At various points over the past forty years, and complicating matters further, new claims have been pressed for the independent disciplinary status of such practices as curriculum studies, school effectiveness and improvement, and leadership. How far can such views be defended, and what turns on these distinctions and rival claims? 


\section{The autonomy of educational research}

It is important to acknowledge the ways in which educational research has not developed as an autonomous, fully self-determining field of study. With any subject there is always a politics of knowledge to be addressed, but in educational research this is particularly salient. Over the past fifty years, the field has been shaped by four main factors. First, there has been the obvious influence of changes in educational policy and practice. New forms of governance as well as fluctuating levels of state intervention, direct and indirect, have had a significant bearing on what it is that is researched and why. Second, there are wider social, political, and technological factors that extend well beyond the control of governments and that constitute powerful forces to which academic research must respond - witness the burgeoning presence of social media as well as the effects of mass migrations. Third, there are more direct influences in the form of changes in the funding of research, especially with a general shift from direct funding to the practice of identifying particular projects and putting them out to tender, where the topic is determined by the sponsor for the research, sometimes with a clear political steer. Fourth, there are influences from developments in the 'parentdisciplines', as these are sometimes called, as well as in other forms of enquiry bearing on education, principally in the social sciences and humanities. In the philosophy of education, one example here is the massive influence of John Rawls on political philosophy, which has understandably ramified into research into such matters as school choice. Another is that of Emmanuel Levinas, whose thematising of alterity has been brought into service in respect of the understanding of other cultures, which is perhaps not the most appropriate and beneficial way of taking up his thought. Another is the rise of neuroscience. Much of such work is well-conceived and valuable, but there are also dangers here. The philosophy of education may become self-demeaning if it constructs itself as always operating only in the wake of major mainstream philosophers; and on a broader scale, in educational research as a whole, there is the danger of hagiography in different forms.

It continues to be true in many contexts that educational research is not forced to give in to political pressures. Of course, there is a need for funding, especially for some kinds of research; non-empirical research is not costly. A more surreptitious influence on behaviour here, however, lies in the kudos and enhanced employment prospects that attach to the winning of research grants. This can muffle research and dull its critical edge. It should not be forgotten that, except in repressive circumstances, critical thought costs nothing. Hence, there is a continuing responsibility to reflect on the policy and practice of education as well as on the ways that the endeavour of educational research is constructed.

In this context there has certainly been much disagreement about the place, status, and credibility of the disciplines. The disciplines, it is said, are self-serving. They install orthodoxies of approach and then impose discipline of an authoritarian kind on anyone who wishes to enter into them, which - if this is true - does indeed render them little different from ideologies. But 
even without the excesses of ideology, the dangers of orthodoxy remain. Like the other disciplines, philosophy of education has sometimes made itself vulnerable to such charges. It has done this especially when it has styled itself as the bastion of reason and defender of the 'citadel of civilisation', and when it has spoken, as it were, de haut en bas to the wider field of empirical research.ii

Vulnerability to ideology - or, at least, to the stagnation of research in orthodoxy and received ideas - is, however, a wider problem. It would be quite wrong to think that these problems of orthodoxy are peculiar to the disciplines: stifling proprieties of thought can emerge in other ways. Lack of rigour and faddishness rightly aggravate the anxiety that, in educational research, anything goes. It is then to the relation between apparently opposing dangers that we should next turn.

\section{Between ideology and anything goes}

Educational research is subject to orthodoxies of old and novel kinds. On the one-hand, the foundation disciplines can become stuck in footnotes to received ideas and over-anxious about reinforcing boundaries. The result is a critical deficit that weakens the 'community of arguers' and undermines the very raison d'être of the practice in question. On the other, new-fangled disciplines, whether justifiably so described or otherwise, seek to legitimate themselves in jargon and deference to new 'authorities' (or the 'latest research findings'). And so again there is a critical deficit.

A key point in Bridges' position is that commitment to truthfulness requires the more-or-less rigorous application of certain procedural rules that help us to see what beliefs are most deserving of confidence, and this seems to be right. But commitment to procedure can also turn into a problem. This is so especially where the sense of the substance of the problem or of the object of enquiry wavers and where there is an attempt to finesse this through focusing on methods. It is usually easier to be clear about methods than it is about the nature of the problem. This is illustrated especially in some current practice in generic research methods courses in education, where attention is turned away from the substantive topic of research and towards protocols of enquiry and the methods themselves. Of course, if a method is adopted, it is important that this should be done consciously and appropriately. One point at issue here is that an excessive focus on such matters can deflect attention from the ostensible substance of concern and perhaps re-cast that substance in terms that make it fit the methodological requirements. Another is that it may elevate those methods to the point that the precision with which they have been adopted will become the subject of evaluation rather than the extent to which the truth of the matter has been revealed, the very purpose they were supposed to serve.

Methods courses typically proceed in this way partly because of the diversity of educational practices towards which research is directed. But there is also here a degree of deference to physical science, with its scope for systematic procedures. This is a problem that extends more broadly across the range of social science. It is, however, self-evident that the lives of 
human beings, including their education, are of a nature that is not susceptible to systematic enquiry in the manner that the physical world is, except in highly circumscribed ways. Human beings can be studied in terms of their biology, and the value of doing this is beyond question. When behaviour is studied - human behaviour especially, but also the behaviour of at least the higher animals - the complexity of life can be seen to extend well beyond the purely physical. The attractions of reductivist forms of behaviourism in psychology lie in part in their clarity of procedure and systematicity. Similar kinds of attraction in other aspects of education have fuelled the trend, over at least the last three decades, towards understanding what is taught in terms of skills and competences, with their pretensions to systematicity, rather than content. The prominence that has been given to transferable skills - as well as communication skills, entrepreneurial skills, information access skills, and many more - and to the amassing of 'skill-sets' reflects a further eliding of the substance of learning and enquiry. Hence, the proceduralist turn in educational research is perhaps a symptom of the age, reflecting a loss of commitment to substantive values and an underlying nihilism, as Nietzsche already saw. There is no doubt that where specific methods are adopted, they need to be applied conscientiously and with rigour. But the proceduralist orthodoxy obstructs or deflects attention from the object of enquiry, and this too is a form of critical deficit.

In this light it is worth reflecting a little on the force of 'foundations' in the present discussion. In its academic usage, the word has connotations of foundationalism - that is, the belief that knowledge claims must rest on firm foundations, on beliefs that are secure. Descartes' cogito is paradigmatic of such a way of thinking. But 'foundation disciplines' or 'the foundations approach', expressions preferred in North America to 'the disciplines approach', iii involve a more or less technical use of the term, and this has no necessary connection with epistemological or ethical foundationalism. North America's most distinctive contribution to philosophy, pragmatism, is explicitly antifoundationalist, and yet one might speculate that there may be a rhetorical appeal to 'foundations' deriving from the founding political importance of the 'Pilgrim Fathers' and the Declaration of Independence. The crucial point, however, is this: the expressions in question refer to kinds of enquiry that are necessary to thinking well about education - necessary because they correlate with the kinds of questions that practices in education should provoke, the addressing of which should be the basis for other more specific forms of enquiry.

When Bridges discusses the relation between the foundation disciplines and les sciences de l'éducation, Allgemeinewissenschaft, and pedagogik, he sets this out well. As we saw at the start, however, much of his discussion does relate to epistemological or other kinds of adherence to foundationalist beliefs, and here he positions himself "neither with the social relativists or subjectivists nor with what are sometimes called the foundationalists, but rather, like Hammersley, with the fallibilist tradition in epistemology associated with, in particular[,] Peirce, Dewey and Wittgenstein' (Bridges 2018). The broad thrust of his position aligns with a Popperian fallibilism, a position that he acknowledges with reference to the 
work of Denis Phillips (see Popper 1968; Phillips 2008). But there is something uncomfortable, to say the least, about this running together of thinkers whose ideas are opposed in certain important respects. Moreover, it is inaccurate to align Dewey and especially Wittgenstein with systematicity. The central idea of the language game in Wittgenstein's Philosophical Investigations is designed to hold back the inclination to impose systematicity on phenomena that are diverse. Human behaviour needs to be seen in the light of 'the whole hurly-burly of human actions, the background against which we see any action' (Wittgenstein 1967: §567). It was not for nothing that Wittgenstein remarked that his motto might have been the line from King Lear: 'I'll teach you differences. 'iv It is a pity when appeal to such philosophers slides so easily into such loose statements as 'all knowledge claims are fallible', where Martin Hammersley is quoted, which a moment's careful thought reveals not to be true. ${ }^{v}$ The paths available to Bridges are diverse, and the forms of relativism are various. It would be good to explore these with more precision.

A further quibble here has to do with the use of the term 'epistemology' itself. In the current climate, talk of 'alternative epistemologies' is apt to transport the discussion into the heady newspeak of 'alternative facts', but it too has functioned in recent decades as a badge of honour for positions taken by those educational researchers who are the target of Bridges' and Horstemke's criticism. But 'epistemology' is fundamentally a meta-level primarily academic term, which refers to theorising about knowledge and belief rather than to the holding or expression of beliefs, etc., themselves. Hence, there may be good reason to speak of what separates the Dogon people from Western peoples, in one of the examples Bridges explores, as 'differences in ways of thinking' rather than 'alternative epistemologies'. Indeed, his own aversion to the latter expression is signalled by its repeated framing in scare-quotes. It is an irony that this taking of positions - say, between foundationalists and alternative epistemologists - seems to have missed the turning away from epistemology (as commonly practised) to which, most of a century ago, Wittgenstein's and Dewey's work contributed so significantly. The holding of positions in this way can displace more agile approaches to these matters, installing in their place a kind of rigor mortis.

The concern about 'paradigm proliferation' expressed by Robert Donmoyer (1996: 19), in a decade marked by the 'paradigm wars' in education research, is a further sign of the ways in which embattled positions are vulnerable to a kind of sclerosis, to the frustration of any community of arguers worthy of the name. Affirmation of the multidisciplinary nature of educational research is sometimes motivated by a suspicion of ivory-tower irrelevance - that is, of certain disciplines in their 'pure' forms. But multi-disciplinarity often fails to face up to the demands of the questions themselves. Deflection from those demands is manifested where a research paper moves from one aspect of, or approach to, a topic to another, without allowing the enquiry to establish any clear line of thought and argument. The semblance of thorough coverage here, accentuated perhaps by an attempt at comprehensive glossing of the literature on the topic and a lengthy list of references, stands in the way of more rigorous 
thought. Deflection is manifested also at the institutional level, where in some respects it seems even to be encouraged: it is assumed that research in education requires the convening of research teams (in the manner of the physical sciences), supported by grants of eye-catching size. Certainly, there are educational research topics that require commitment along these lines, but there is also a range of fundamental problems in relation to which the research team approach is likely to be a barrier to successful enquiry. Too often the approach lays the way for superficiality, and so, once again, there is a critical deficit.

Multi-disciplinarity does, however, make sense, whereas postdisciplinarity does not. Multi-disciplinarity and inter-disciplinarity are often needed - in diverse fields of research and practice, ranging from civil engineering and medicine to education itself; and they presuppose the existence of more or less discrete disciplines that can work together. The more murky but fashionable notion of postdisciplinarity, by contrast, implies a dispensing with the disciplines: it is motivated typically by a dissatisfaction with the restrictions of their practices and lines of thought, sometimes by a more headstrong dismissal of the presuppositions of truth and of the possibility of objectivity that define them, and at times, so it seems, by advocacy for free-thinking novelty. vi As was acknowledged above, there is reason to be suspicious of the disciplines where these become overly self-protective; lapses into orthodoxy inevitably dull their means of criticism, and this is especially lamentable given that the focusing and advancement of reasoned criticism is central to their raison d'être. It is right also to question them when, instead of acknowledging their complementary role in education, they turn into rivals. There may be understandable institutional reasons for this (say, competition over funding or appointments), but in academic terms it is not justifiable. Furthermore, the disciplines that have a bearing on education are best understood when it is recognised that the boundaries between them are not water-tight and where natural overlaps between them are recognised. Yet when the reaction against disciplines turns sometimes into advocacy for post-disciplinarity, the dangers are twofold. First, there is a question concerning what will constitute the procedural rules of reasoning and argument that Bridges rightly identifies as important. Second, it is not clear how, in their absence, a sustained form of enquiry can be generated. Let me qualify this a little, however, for it may seem that the present argument has now itself lapsed into the proceduralism that is otherwise partly called into question in my discussion. Here again, perhaps, I part company with Bridges' account.

It does not seem sufficient to understand the cogency and credibility of a discipline in terms of the procedural rules to which Bridges refers. In the first place, it is important to say that there must be some kind of continuity in the substantive focus of attention - that is, in the discipline's taking up of certain kinds of topics and problems as its concern. What is required also is some continuity in relation to the inheritance of certain texts that practitioners in the discipline have found significant and around which, to put this another way, they have gathered. A division of a kind opens in philosophy between two conceptions of the subject: as a set of problems to be solved and as a series of texts to be read. This is not a water- 
tight distinction: the question is one of relative emphasis, and the way this is answered will position philosophy, on the one hand, as something like a science and, on the other, as more fully realised amongst the humanities. (To some extent, the distinction maps on to the familiar, cumbersome, and obstructive contrast between, respectively, analytical and continental philosophy, but it would be wrong to see it primarily in thee terms, and the descriptive power of the contrast between problems to be solved and texts to be read perhaps gives it more purchase.)

Yet a further factor that needs acknowledgement here has to do with the importance of actual differences in cultural practice in research in education, including the part that language difference plays. The politics of knowledge is thus played out most significantly in the institutional forms in which research into education and the preparation of teachers have taken place. It is plain that the structures relating to the latter vary considerably from country to country, and this has a significant bearing on how careers in education(al research) are constructed and shaped. These are important matters, but perhaps more salient for the present discussion is the way in which education as an academic subject, as the topic of enquiry and research, is institutionalised. The history of this subject varies significantly internationally, and the terms that are used in relation to it are not consistent. The problematically elastic term 'education' in English contrasts with the variety of expressions that are found in, for example, German and Scandinavian languages. English has the term 'pedagogy', but until perhaps thirty years ago it was not an expression one heard often amongst teachers themselves, and now, where it is used, it refers most commonly to teaching method or approach, at a relatively practical level. For example, whole-class teaching and group work might be said to constitute different pedagogies - a usage that may well strike those whose first language is not English as somewhat banal. When, in 1981, Brian Simon asked the question 'Why no pedagogy in England?' (Simon, 1981), he was lamenting the absence of the kind of study and enquiry that has gone by that name in many European jurisdictions. Just over two decades later, Robin Alexander painted a still more dreary picture of policy regarding these matters, especially in the light of the vulnerability of expressions of purpose and principle to political spin: 'The pedagogy of principle has yet to be rescued', he wrote, 'from the pedagogy of pragmatism and compliance' (Alexander 2004: 29). This is the antithesis of pedagogy as it has been understood in the traditions to which Simon refers. These have not, it seems, come naturally to Anglophone cultures, very much to their cost; and the politics of knowledge has been such that pedagogy, in this rich sense, has not found a footing in name in the practices of teacher education or in research. In the past at least, pedagogy in the European contexts referred to here has been sustained by the gathering of thought around series of texts and problems, and hence has realised the continuities of enquiry to which reference is made above. Bridges is right to see this as incorporating elements of the four disciplinary approaches typical of Anglophone cultures.

An important implication of my discussion thus far is that there is an internal relation between discipline, rigour, and coherence, and these, though not systematicity, are requirements of argument. In view of the 
problems Bridges identifies, it is certainly important that criticism of a philosophical kind is promoted. Whether this is carried out under the name 'philosophy' or 'pedagogy' or under some other rubric is, in a sense, a secondary matter. But the significance of a name should not be underestimated, especially in prevailing contexts where policy and practice are so vulnerable to political spin and to the deft strategic placing of key terms, in the wider culture and within the university itself. And in the light of this it is appropriate to ask what can be expected from the philosophy of education as a form of disciplined enquiry?

\section{Philosophy of education as disciplined enquiry}

Philosophy of education is subject to two assumptions, both of which need to be undermined.

The first is that it is a branch of philosophy, similar to the philosophy of science or the philosophy of music. Branches address a field of concern that is relatively easily circumscribed, and they involve concepts and ways of reasoning that, although not entirely discrete and although derivative in some degree from the broad trunk of philosophical thought, are in some measure distinctive of that field. They are branches in that they grow from more fundamental, central elements in philosophy - such as ethics, epistemology, metaphysics, and ontology. Branches sometimes relate to professional fields of practice and enquiry, and this would be so with the philosophy of education. Hence, it is not surprising that it is often seen in this way. There are, however, serious problems with this view. It needs to be noticed, first, that there is no branch of philosophy that is not relevant to the philosophy of education in some way. The philosophy of science is relevant to teaching and learning in science, just as the philosophy of music has significance for music education. Probably the connections are wider than this observation implies. Furthermore, these branches, like all forms of enquiry, themselves involve education - the pursuit of learning within the subject - such that any separation of them from education must be artificial or at least unwieldy. A more important consideration, however, has to do with the nature of philosophy itself. If one thinks of central elements in the mainstream of philosophy, such as ethics and epistemology, it is reasonably clear that they are concerned not just with the nature of the good or the nature of knowledge but with how one comes to live a good life and how one comes to know something. In other words, questions of education, of teaching and learning, are already there at the heart of philosophy, as is testified at the start of philosophy, in the work of Plato himself. Given the reach and intensity of philosophy's concern with what it is to be a human being, how could this not involve questions about how we become what we are, which is to say questions about our education?

The second common assumption is that the philosophy of education is an applied field. This may be an attractive way of thinking in some respects, especially at a time when philosophy and the humanities more generally are under pressure to show their practical importance. There should certainly be no doubt about the desirability of considering practical questions in education philosophically, but there is reason to question the idea of 
philosophy as something 'applied'. The expression falls into the accustomed pairing and purported contrast of 'theory' and 'practice', and this gives rise to a somewhat mechanistic conception of what the work of philosophy must be: philosophy does the theory (understood perhaps as conceptual analysis or as theory-building), and then this is applied in practice. An influential, extreme version of this view in relation to education was found in the work of John Wilson, for whom the only thing that philosophy could do in relation to education was to clarify such basic concepts as teaching, learning, indoctrination, authority, and education itself - that is, to reveal their essential components - so that these would then provide the foundation for the development of educational policy and practice. ${ }^{\text {vii }}$ Yet this way of thinking can involve a kind of denial of responsibility - after all, it is simply the logic of education that is being revealed, and the philosopher is scarcely responsible for the way things are. And it can also be characterised, as we saw above, by a certain hauteur: the philosopher does the serious theoretical work, and the practitioner applies this in practice. Clearly this is to fall short of the practical reason that was advanced by Aristotle, just as it is to miss the inherent philosophical interest in teaching and learning as essential aspects of the human condition. The mechanistic dichotomisation of theory and practice generates confusion around both.

If these assumptions are dispelled, it can be seen that philosophical questions are stubbornly there in educational practice. Conversely, there is no getting around the fact that education raises questions at the heart of philosophy. Such questions are, in a sense, unavoidable for human beings, explicitly so in a democracy. It is not that philosophy has a unique command of these things, but philosophy is constituted by sustained traditions of enquiry into such matters. Responses to its questions are not generally advanced in the manner of scientific progress, with an accumulation of knowledge, but this in no way makes them superfluous. In a sense these are questions that the members of each generation must take up for themselves, as the humanities attest in various ways. That the questions remain live and, in a sense, continually present themselves in new ways does not deny the fact that the attention given to them through the generations can contribute powerfully to the responses that can be given today. That they are live in teaching and learning means that philosophical reflection on and within these practices - rather than the application of theories to these practices - can be peculiarly illuminating.

There is, however, a prevailing empiricism viii that contends that this is not so. When, in a keynote at the Vienna meeting of the European Conference in Educational Reserch in 2009, Roland Reichenbach reasserted the importance of philosophy in educational research, he faced a barrage of questions along the following lines: "What is the empirical basis for your claims?", "How do you know?", and "Where are your data?" Some shook their heads at the responses he made, which seemed to rely on argument and the appeal to reason alone, not on something that could be presented as evidence. But such a reaction is not sound. The obvious fallacy in such views has two main aspects. First, any form of empirical research must take place on the basis of priorities and commitments that are not themselves the products of empirical research, not to mention the fact that, especially in 
social science subjects, the results of empirical enquiry will typically be exposed to forms of analysis and interpretation that extend beyond a simple reading off of results: the data do not generally speak for themselves.

Second, empiricism fails to acknowledge that there are some questions that cannot be addressed through empirical means. Questions concerning value and concerning the nature of the good, as well as questions of justification (including the question that any empirical researcher must face of why their particular topic is worth pursuing at all), are not answerable by empirical enquiry. To condemn empiricism is emphatically not to criticise empirical research, but it is to oppose the ideological belief that it is only through empirical research that education can be understood and advanced (Standish, 2016a). In my own ECER keynote, in Dublin in 2016, which was entitled 'Empiricism and the Avoidance of Philosophy' (2016b), I pursued a line of thought similar to that of Reichenbach. Some very interesting questions were raised in response, but these were mostly sympathetic to what I had said. I was puzzled not to be facing the same barrage of criticism that had confronted Reichenbach. Did that mean that the battle had been won? It would be pleasing but fanciful to think that this was so. Given that empiricism has taken over so many positions of influence, however, why is it so hard to find any reasoned defence of it?

Bridges' concerns are certainly of a different order, being focused primarily on the lack of coherence and consistency amongst those who are indeed committed to philosophical work of some kind, and the hope that greater clarity or agreement over the criteria of good philosophical work might aid in the wider understanding of philosophy's contribution to education is not be an idle one. The impression might be gleaned from his account that what is most required in order to legitimate the research and give it coherence is the rigorous following of procedures of reasoning. While this is true up to a point, it frames the matter too narrowly, in the way that we saw in an extreme form in Wilson, and this is to fall short of providing an accurate picture of reason itself. It gives the impression that one has only to turn the wheels of logical argument, and the desired result will be produced. While matters can indeed sometimes be resolved through such procedures, it is also the case that the success of an argument in leading to the truth will depend not only upon its validity (that the propositions follow the rules of logical inference) but also on the truth of the premises (those propositions taken as the starting point of the argument). And often the real difficulty in thinking - about education, as with so many aspects of our social world - is to find premises, starting-points, that do justice to the reality of the circumstances. The truth of a premise will need to be assessed not as a proposition in isolation but in relation to the broader context in which it is constructed. Crucial in this is the exercise of judgement, where this is not a matter of the accurate application of a rule. Good judgement is typically developed through experience, and it is refined through our interaction with others and through the testing of responses against the reactions and views of others. Such practice often involves laying one example against another and seeing differences and connections. The refinement is extended where one considers one's judgement in relation to histories of response to similar circumstances, in an ongoing conversation with others and between 
generations. High points in this conversation have come down through the ages in cStandishs of classic writings or, to put it in more Deleuzian vein, in those landmark texts around which thought and criticism gather. ${ }^{\text {ix }}$ Without this deepening of the notion of reason, there is a danger that rigour becomes a badge of honour for philosophy of a certain kind, whose effects derive more from the rhetorical conviction with which it is espoused than from its basis in reason.

My own view is that there are no quick routes to be taken here and that the recourse to proceduralism is generally symptomatic of a loss of nerve. For Nietzsche, it was a dimension of the nihilism that he diagnosed in the bourgeois world around him. Performativity in education is a derivative of that nihilism.

I want to draw this discussion to a close by trailing the thought that the hegemony of English - both as the prevailing 'world language' and as the dominant language of educational research - exacerbates the tendency towards the procedural and itself has potentially nihilistic effects. Rigour, as I have begun to show, requires rather more attention to language difference, and indeed Bridges' title for the ECER symposium, 'European educational research: Conversational community or Tower of Babel?', aptly turns the attention towards what is at issue here.

\section{Translation, untranslatability, and the possibilities of thought}

On the occasion of the symposium, Bridges provided a brief anecdote that nicely sets the scene for his own concerns about these matters. 'Mino Conte and Volker Kraft . . . were trying to explain to me', he recounts, 'that the British could never properly understand the distinction between Bildung and Erziehung or educazione and formazione because they had not had the experience of living under fascism' (Bridges 2017). The power of the example lies in its suggestion of the link between language and political experience. Sensitivity to this should raise concerns about the dominance of English in new ways. In academic circumstances where English is so often taken as the lingua franca, it is entirely right to acknowledge the advantage that native speakers of the language enjoy, not least when it comes to publication. It is reasonable to assume also that the hegemony of English gives undue influence to monolingual Anglophone cultures and that the frameworks of thinking that English enables risk obscuring other ways of seeing the world. The terms that Conte and Kraft highlight are powerful indicators of blindspots in English and perhaps in English-speakers generally, whether such limitations are the products of specific histories as is claimed here or something more elusive within the language itself. I leave Conte and Kraft's point to stand in relation to the former, but let me venture some thoughts about the latter.

The term 'teacher' in English opens a semantic field somewhat different from maître in French or, more clearly, from sensei in Japanese. The French and Japanese terms seem less likely, for example, to transmute into the blandness of 'facilitator', in that they retain auras of richness and respect that 'teacher' has to some extent lost. One might think also of the relation between Wetenschappen, in Dutch, and 'science', where the latter's 
contemporary connotations are still, first and foremost, with the physical sciences. The German Geisteswissenschaften has no straightforward English equivalent. And, to take a final example, the English term 'apprenticeship', which has a semi-technical meaning and which has gained a new influence in policy recently, is narrow and restricted by contrast with the more everyday Spanish term aprendizaje and its equivalents in Romance languages. So the general point here is that where the English term becomes current - and where perhaps it is a mark of sophistication, even simply of competence today, for a non-native speaker of the language to be adept in its use - there is likely to be a surreptitious displacement of one set of connotations and associations in favour of another, with the English expressions having the lion's share of influence.

Beyond such cases, however, there are grammatical differences between languages that encourage a different structuring of thought. English lacks the ease with compound words of German and the middlevoiced verbs found, for example, in Greek. Its familiar, somewhat plodding subject-verb-object structure facilitates thought of a particular kind. Utitilitarianism arose in England against a background of industrial and demographic change, where appalling social conditions demanded largescale systematic approaches. But is it merely a coincidence that this occurred in an English-speaking context? Are there features of the language that precipitated the kind of practicality that was called for there and then. And does that insistent grammatical structure harden dichotomised subjectobject relations in a way that more middle-voiced grammars escape? A further point to be made here is that the lingua franca of so much research is not exactly English but English-as-a-second-language, one characteristic of which is that, for most of its speakers, it is severed from the language of home and intimacy. If there is a utilitarian, technical bent to the Anglophone construction of educational research, this is likely to be accentuated where the language that is favoured and promoted in the international community is procedural and systematic, especially where this is shared by speakers whose usage is cut off from those richer or more intimate counter-balances of thought. A technical language, after all, presents fewer problems of translation.

These are problems, but they also harbour opportunities. Non-native speakers of English are in one respect at an advantage over native-speakers in that they continually experience the space of judgement that is opened by translation - crossing different conceptual fields and disparate grammatical forms. This itself is an opening of thought to which the native speaker may be oblivious. Translation involves an exercise of judgement that is not governed by systematic procedures or definitive rules, and where rigour will be achieved by sensitive attunement to context and to the significance of words. Hence, it is to the benefit of educational research when attention is drawn thoughtfully to such difficulties in translation, and this can be invaluable in holding back the deleterious, technicising tendency described above. If this puts native speakers of English at a disadvantage, there may nevertheless be a gain for them: in increased humility. This might be ironic, but it would not be before time. Conte and Kraft's remark illustrates how and why this might be done. 
The path between subjectivism and foundationalism that Bridges has sought may open more readily to languages where the idea of the human subject is not constituted within sclerotic dichotomous relations. Indeed, a part of Wittgenstein's purpose has been said to be the finding of different and better ways of thinking of subject-object relations, as of subjectivity and objectivity (Cavell 1979 - see, especially, p. 329). Such a direction of thought also characterises so much of poststructuralism, especially insofar as those thinkers that are embraced by this term are committed to understanding the centrality of language in human life and the world: such understanding undermines the notion of the sovereign subject and weakens the hold of the fact-value divide, both of which have tended to dominate so much Anglophone philosophy and to contribute to its nihilistic aspects and effects.

Nietzsche's remark that truth is a woman is an appeal to a feminine archetype. Its implication is that truth may be less amenable to thought that seeks to grasp directly. The truth may require a more indirect way of thinking, in which, far from hastening to master things calculatively and assertively, a practice of thought is developed that is more receptive and responsive, a practice that allows the truth to be revealed (see Standish, 1992, 2014). There are no clear-cut procedures for this, which is certainly not to say that nothing can be taught here or that no progress can be made. Neither is there any system, which is not to say that no discipline is required. Philosophy at its best embraces such possibilities of thought, and in its absence the understanding of education through research will surely be the poorer.

\section{References}

Alexander R (2004). Still no pedagogy? Principle, pragmatism and compliance in primary education, Cambridge Journal of Education, 34(1).

Bridges D (2018). 'Rigour', 'discipline' and the 'systematic' in educational research - and why they matter, European Journal of Educational Research, this issue.

Bridges D (2017). Introduction to 'European educational research: Conversational community or Tower of Babel?' Symposium. European Conference in Educational Research, Copenhagen.

Cavell S (1979). The Claim of Reason: Wittgenstein, Skepticism, Morality, and Tragedy. Oxford: Oxford University Press.

Deleuze G and Guattari F (1996/1991). What is Philosophy? New York: Columbia University Press.

Donmoyer R (1996). Educational research in an era of paradigm proliferation: What's a journal editor to do? Educational Researcher, 25(2): 19-25.

Horsthemke K (2017) '\#FactsMustFall'? - Education in a post-truth, post truthful world. Ethics and education 12(3): 277-288.

Hunt L (1991). History as gesture; or the scandal of history. In Arac J and Johnston B (eds) Consequences of theory. Baltimore: Johns Hopkins University Press, pp. 91-107.

Nietzsche, F (2003 [1886]). Beyond Good and Evil. Translated by RJ Hollingdale. Revised edition. Harmondsworth: Penguin Classics. 
Nietzsche, F (1974 [1882]) The Gay Science, with a prelude in rhymes and an appendix of songs. Translated, with commentary, by Walter Kaufmann. New York: Random House.

Phillips D (2008). Subjectivity and objectivity: An objective inquiry. In Hammersley M (ed.) Educational research: Current issues. London: Paul Chapman and the Open University, pp. 57-72.Popper K (1968). Conjectures and refutations. New York: Harper.

Simon B (1981). Why no pedagogy in England? in: B Simon and W Taylor (eds) Education in the eighties: The central issues. London: Batsford, pp. 124-145.

Standish P (2018). Rigour and Recoil: Claims of Reason, Failures of Expression. Journal of Philosophy of Education 52(4): 609-626

Standish P (2016a). Making Sense of Data: Objectivity and Subjectivity, Fact and Value. Pedagogika 6: 622-637.

Standish P (2016b). Empiricism and the Avoidance of Philosophy. Video of keynote lecture, European Conference in Educational Research, Dublin 2016. Online at: https://www.youtube.com/watch?v=v0_pxNP5xtg Accessed 28 September 2018.

Standish P (2014). Impudent Practices. Ethics and Education. 9(3): 251-263.

Standish P (2012a). 'THIS is Produced by a Brain-Process!': Wittgenstein, Transparency and Psychology Today. Journal of Philosophy of Education 46(1): 60-72.

Standish P (2012b). Transparency, Accountability, and the Public Role of Higher Education. Educationalfutures, 4(4).

Standish P (2007.) Rival Conceptions of the Philosophy of Education. Ethics and Education. 2(2), 159-171.

Standish P (2006). John Wilson's Confused 'Perspectives on the Philosophy of Education'. Oxford Review of Education 32(2): 265-279.

Vansieleghem N (2005) Philosophy for Children as the Wind of Thinking. Journal of Philosophy of Education 35(1):19-35.

Wilson J (1979). Preface to the Philosophy of Education. London: RKP. Wilson J (2003). Perspectives on the Philosophy of Education. Oxford Review of Education. 29: 279-293.

Wittgenstein L (1967). Zettel. Translated by G.E.M. Anscombe. Oxford: Basil Blackwell.

\footnotetext{
i Nietzsche takes up these themes in, for example, The Gay Science (1974 [1882]) and Beyond Good and Evil (2003 [1886]).

ii For a discussion of different conceptions of the philosophy of education, see Standish (2007).

iii Typically, these are known as 'the foundations' in North America and as 'the disciplines' in the UK. The standard assumption is that they comprise the history, philosophy, psychology, and sociology of education.

iv These are the words of the Earl of Kent to King Lear (King Lear, Act 1, scene 4).
} 
$\checkmark$ For example, the statement that the internal angles of a triangle add up to 180 degrees is necessarily true. This is part of what 'triangle' means. Other statements, such as that the English word 'true' has four letters, make fallibilism in this extreme form look implausible.

vi The $3^{\text {rd }}$ International Conference on Postdisciplinary Approaches styles its purpose as follows: "The theme for our Auckland gathering is Knowledge as Disobedience, Expression and Creativity.

We welcome all types of presentations that address postdisciplinarity in a range of contexts - including, but not limited to, epistemology and knowledge production, practice and action, ways of being and becoming, and relational theory. We particularly encourage non-western perspectives vis-à-vis oral literature, art and performance. Postdisciplinarity has been previously articulated as an invitation to different interpretations, critical analysis, and creative problem solving - extending also to questioning conventional processes of knowledge making.' Online at: http://www.postdisciplinary.net/. Accessed: 30 September 2018. vii RS Peters was wont to use such phrases. For discussion of the relation between the extremes of ideology and anything goes, see John Wilson (1979, 2003) and Standish (2006).

viii The term 'empiricism' is being used here not in the technical sense found in epistemology, where it contrasts with 'rationalism', but in a pejorative sense, the force of which the paragraph makes clear.

ix See Gilles Deleuze and Félix Guattari (1996), who write of such landmarks as dry-stone walls: the substantial but porous nature of constructions of this kind makes them long-lasting by enabling the wind to pass through them. Socrates speaks of the 'wind of thinking' (see Vansieleghem, 2005), and this might license us to think not only of the flow of thought through the reading of such classic works but also of ideas that live and grow in their hollows and interstices. 